\title{
Soot Surface Growth in Laminar Hydrocarbon/Air Diffusion Flames
}

\author{
A.M. El-Leathy ${ }^{*}$, F. Xu ${ }^{\dagger}$, C.H. Kim ${ }^{\ddagger}$ and G.M. Faeth ${ }^{\S}$ \\ The University of Michigan, Ann Arbor, Michigan 48109, U.S.A.
}

\begin{abstract}
The structure and soot surface growth properties of round laminar jet diffusion flames were studied experimentally. Measurements were made along the axes of ethylene-, propylenepropane- and acetylene-benzene-fueled flames burning in coflowing air at atmospheric pressure with the reactants at normal temperature. The measurements included soot structure, soot concentrations, soot temperatures, major gas species concentrations, some radial species $(\mathrm{H}, \mathrm{OH}$ and $\mathrm{O}$ ) concentrations, and gas velocities. These measurements yielded the local flame properties that are thought to affect soot surface growth as well as local soot surface growth rates. When present results were combined with similar earlier observations of acetylene-fueled laminar jet diffusion flames, the results suggested that soot surface growth involved decomposition of the original fuel to form acetylene and $\mathrm{H}$, which were the main reactants for soot surface growth, and that the main effect of the parent fuel on soot surface growth involved its yield of acetylene and $\mathrm{H}$ for present test conditions. Thus, as the distance increased along the axes of the flames, soot formation (which was dominated by soot surface growth) began near the cool core of the flow once acetylene and $\mathrm{H}$ appeared together and ended near the flame sheet when acetylene disappeared. Species mainly responsible for soot oxidation $-\mathrm{OH}$ and $\mathrm{O}_{2}-$ were present throughout the soot formation region so that soot surface growth and oxidation proceeded at the same time. Present measurements of soot surface growth rates (corrected for soot surface oxidation) in laminar jet diffusion flames were consistent with earlier measurements of soot surface growth rates in laminar premixed flames and exhibited good agreement with
\end{abstract}

\footnotetext{
Research Associate, Department of Aerospace Engineering.

${ }^{\dagger}$ Research Associate, Department of Aerospace Engineering; currently Assistant Professor, Department of Mech., Mtls. and Aero. Engr., University of Central Florida, Orlando, FL 32816.

${ }^{\ddagger}$ Graduate Student Research Assistant, Department of Aerospace Engineering.

${ }^{\S}$ A.B.M. Modine Professor, Department of Aerospace Engineering; Fellow AIAA.
} 
existing Hydrogen-Abstraction/Carbon-Addition (HACA) soot surface growth mechanisms in the literature with steric factors in these mechanisms having values on the order of unity, as anticipated.

\section{Nomenclature}

$\mathrm{d}_{\mathrm{p}} \quad=\quad$ mean primary soot particle diameter $(\mathrm{m})$

$\mathrm{f}_{\mathrm{s}} \quad=$ soot volume fraction $(-)$

[i] $=$ concentration of species $\mathrm{i}\left(\mathrm{kgmol} \mathrm{m}^{-3}\right)$

$\mathrm{R}_{\mathrm{i}}=$ terms in the HACA soot surface growth rate formulas $\left(\mathrm{kg} \mathrm{m}^{-2} \mathrm{~s}^{-1}\right)$

$\mathrm{T}=$ temperature $(\mathrm{K})$

$\mathrm{u}=$ streamwise velocity $\left(\mathrm{m} \mathrm{s}^{-1}\right)$

$\mathrm{w}_{\mathrm{g}}=$ soot surface growth rate $\left(\mathrm{kg} \mathrm{m}^{-2} \mathrm{~s}^{-1}\right)$

$\mathrm{z}=$ streamwise distance $(\mathrm{m})$

$\alpha_{i}=$ empirical (steric) factors in the HACA soot surface growth rate formulas (-)

$v \quad=$ kinematic viscosity $\left(\mathrm{m}^{2} \mathrm{~s}^{-1}\right)$

$\phi \quad=\quad$ fuel-equivalence ratio $(-)$

Subscripts

$\mathrm{CH}=\mathrm{HACA}$ soot surface growth mechanism of Colket and Hall ${ }^{17}$

$\mathrm{FW}=$ HACA soot surface growth mechanism of Frenklach and coworkers ${ }^{18-20}$

\section{Introduction}

Soot is a major unsolved combustion problem because it is present in most hydrocarbonfueled nonpremixed (diffusion) flames and current understanding of soot processes in flame environments is limited. This lack of understanding inhibits progress toward developing reliable methods of computational combustion, predictions of pollutant soot emission properties and estimates of flame radiation properties, among others. Motivated by these observations, the 
present investigation sought to extend earlier studies of soot processes in laminar premixed and diffusion flames completed in this laboratory, ${ }^{1-8}$ using similar methods. The specific objectives of the present investigation were to obtain new experimental information about the structure and soot surface growth properties of hydrocarbon-fueled laminar jet diffusion flames burning in air at atmospheric pressure with the reactants at normal temperature; and to exploit these results to evaluate contemporary models of soot surface growth properties in flame environments. The following description of the research is brief; more details and a complete tabulation of the measurements are provided by $\mathrm{Xu}^{9}$ and EI-Leathy. ${ }^{10}$

Earlier studies of the structure and soot surface reaction properties of laminar flames have been reviewed by Haynes and Wagner, ${ }^{11}$ Howard, ${ }^{12}$ Richter and Howard, ${ }^{13}$ and Kennedy $;{ }^{14}$ therefore, present considerations of earlier work will be brief and will emphasize past studies in this laboratory that have motivated the objectives and methods of the present investigation. Sunderland and coworkers ${ }^{1-3}$ experimentally studied the structure and soot surface growth properties of laminar hydrocarbon-fueled (acetylene, ethane, propane, n-butane, propylene and 1,3-butadiene) diffusion flames burning in air at pressures of 10-100 $\mathrm{kPa}$, however, they were not able to evaluate available mechanisms of soot surface growth because their measurements did not provide information about $\mathrm{H}$ concentrations needed by the theories. Xu and coworkers ${ }^{46}$ subsequently completed experimental investigations of the structure and soot surface growth properties of laminar premixed flames at atmospheric pressure including ethylene/air mixtures similar to the flames studied by Harris and Weiner ${ }^{15}$ and methane/oxygen mixtures similar to the flames studied by Ramer et al. ${ }^{16}$ Concentrations of $\mathrm{H}$ were found during these studies so that the measurements could be used to evaluate the Hydrogen-Abstraction/Carbon-Addition (HACA) soot surface growth mechanisms of Colket and Hall ${ }^{17}$ and Frenklach and coworkers. ${ }^{18-20}$ It was found that the HACA soot surface growth mechanisms provided excellent correlations of the measurements using quite reasonable values of unknown empirical steric factors that appear in 
the theories. Xu and Faeth ${ }^{7}$ extended study of soot surface growth from premixed flames to acetylene-fueled laminar jet diffusion flames burning in air at atmospheric pressure, using the full suite of measurements developed during the laminar premixed flame studies of Refs. 4-6. These results showed that soot surface growth rates in laminar premixed and diffusion flames satisfied similar reaction rate expressions and that these expressions were well represented by the HACA mechanisms of Colket and Hall ${ }^{17}$ and Frenklach and coworkers. ${ }^{18-20}$ Finally, Xu et al. ${ }^{8}$ established that soot surface oxidation in laminar diffusion flames, at fuel-rich and nearstoichiometric conditions, involving a variety of hydrocarbon fuels (acetylene, ethylene, propylene, propane, and benzene) was dominated by the reaction of the soot surface with $\mathrm{OH}$, and could be correlated effectively by estimating the oxidation rate due to $\mathrm{O}_{2}$ using the classical expression of Nagle and Strickland-Constable ${ }^{21}$ (whose results were later confirmed by Park and Appleton $^{22}$ ) combined with an oxidation rate due to $\mathrm{OH}$ that had very nearly the same collision efficiency as the results of Neoh and coworkers ${ }^{23-25}$ based on measurements in soot-containing premixed flames. This finding is also in fair agreement with earlier measurements of soot surface oxidation rates by $\mathrm{OH}$ in diffusion flames at atmospheric pressure due to Garo et al. ${ }^{26,27}$ and Haudiquert et al. ${ }^{28}$

Naturally, there have been many other studies of the structure and soot reaction processes of laminar hydrocarbon-fueled diffusion flames, seeking detailed models of their properties, see Balthasar et al. ${ }^{29}$ Bai et al.$^{30}$ and references cited therein. Early measurements of the structure and soot reaction processes of laminar diffusion flames include the studies of Mitchell et al.,, Santoro and coworkers, ${ }^{32-36}$ Saito et al. ${ }^{37}$ and many others reviewed by Haynes and Wagner, ${ }^{11}$ Howard, ${ }^{12}$ and Richter and Howard. ${ }^{13}$ Additional work along these lines due to Garo et al., ${ }^{26,27}$ Haudiquert et al. ${ }^{28}$ and McEnally and coworkers, ${ }^{38-41}$ involve sophisticated probe and nonintrusive measurements within soot-containing laminar diffusion flame environments. None of these studies, however, involve the full suite of measurements used by $\mathrm{Xu}$ and coworkers ${ }^{4.8}$ 
within laminar premixed and diffusion flames, that is needed to evaluate theories of soot growth along the lines of Colket and Hall ${ }^{17}$ and Frenklach and coworkers. ${ }^{18-20}$

Based on this status, the present investigation sought to improve understanding of the structure and soot surface growth properties of diffusion flames, by experimentally studying coflowing laminar jet diffusion flames burning in air at atmospheric pressure but considering hydrocarbons other than acetylene as the fuel in order to explore potential modifications of the soot surface growth mechanism when the fuel was no longer a species that is a direct reactant of the HACA soot surface growth mechanism (e.g., ethylene, propylene, propane, and benzene were considered as fuels), which is the case for acetylene that was considered earlier by Xu and Faeth. ${ }^{7}$ In particular, benzene was considered in order to study the behavior of fuels more closely related to Polycyclic Aromatic Hydrocarbons (PAH) than the other fuels that were studied because PAH soot surface growth mechanisms have been proposed as an alternative to HACA soot surface-growth mechanisms, see Howard, ${ }^{12}$ Richter and Howard, ${ }^{13}$ and references cited therein. In addition, corrections of soot surface growth rates to account for effects of soot surface oxidation were improved compared to earlier work, e.g., Refs. 4, 5 and 7, by exploiting the recent findings concerning soot surface oxidation rates in laminar diffusion flames at atmospheric pressure reported by Xu et al. ${ }^{8}$

To summarize, the specific objectives of the present study were as follows: (1) to measure the structure (temperatures, stable and radical species concentrations and velocities) and soot properties (soot volume fractions and primary soot particle diameters) within the soot formation region of hydrocarbon-fueled laminar diffusion flames burning in air, and (2) to exploit both the new measurements, along with results from existing measurements in premixed flames ${ }^{4,5}$ and acetylene-fueled diffusion flames, ${ }^{7}$ to evaluate and correlate the HACA soot surface growth mechanisms of Colket and Hall ${ }^{17}$ and Frenklach and coworkers. ${ }^{18-20}$ The study was limited to measurements along the axes of buoyant laminar jet diffusion flames burning in 
coflowing air at atmospheric pressure, similar to earlier studies of soot processes in diffusion flames in this laboratory due to Sunderland and coworkers ${ }^{1,2}$ and $\mathrm{Xu}$ and coworkers ${ }^{7,8}$

\section{Experimental Methods}

\section{Test Apparatus}

Experimental methods were similar to Xu and coworkers ${ }^{7,8}$ and will only be described briefly. The same burner was used to observe soot processes in laminar diffusion flames and to calibrate the $\mathrm{H}$ concentration measurements using a laminar premixed flame. The burner had a $34.8 \mathrm{~mm}$ diameter inner port both for the fuel stream of the diffusion flames and for the methaneoxygen-nitrogen reactant mixture of a premixed calibration flame that was used to calibrate present measurements of some radical species $(\mathrm{H}, \mathrm{OH}$ and $\mathrm{O})$. A $60 \mathrm{~mm}$ diameter coannular outer port was used both for the dry air coflow of the diffusion flames and for the nitrogen coflow of a premixed calibration flame. The dry air coflow of the diffusion flames served to eliminate natural convection instabilities, to avoid problems of argon in natural air eluting with $\mathrm{O}_{2}$ during gas chromatography measurements, and contamination of the flames with the small levels of $\mathrm{CO}_{2}$ and water vapor that are present in natural air. The nitrogen coflow of the premixed calibration flame served to eliminate the annular diffusion flame for this fuel-rich premixed flame in order to improve the accuracy of the $\mathrm{H}$ concentration calibration.

Burner gas flow rates were measured with rotameters. Mixtures were allowed to mix within feed lines that were at least 1000 diameters long to ensure that they were uniform. The flames burned in a room air environment with room disturbances controlled by surrounding them with several layers of screens and a plastic enclosure. The burner could be traversed horizontally and vertically in order to accommodate rigidly-mounted optical instrumentation. 


\section{Instrumentation}

Present measurements were similar to $\mathrm{Xu}$ and coworkers ${ }^{7,8}$ and will only be described briefly. The following properties were measured along the axes of the test flames: soot volume fractions, flame temperatures, concentrations of major gas species, gas velocities and concentrations of some radial species $(\mathrm{H}, \mathrm{OH}$ and $\mathrm{O})$.

Soot volume fractions were measured by deconvoluting laser extinction measurements at $632.8 \mathrm{~nm}$ for chord-like paths through the flames. This data was reduced using the refractive indices of Dalzell and Sarofim ${ }^{42}$ for consistency with past work, ${ }^{1 \cdot 7}$ however, these refractive index values have recently been confirmed by Krishnan et al. ${ }^{43}$ The experimental uncertainties (95\% confidence) of the soot volume fractions are estimated to be smaller than $10 \%$ for soot volume fractions greater than $0.02 \mathrm{ppm}$, increasing inversely proportional to the soot volume fraction for smaller values.

Soot and gas temperatures are essentially the same; therefore, soot (gas) temperatures were measured by deconvoluting spectral radiation intensities for chord-like paths through the flames. Temperatures were computed based on spectral radiation intensities at several wavelength pairs, as follows: 550/700, 550/750, 550/830,600/700,600/750,600/830 and $650 / 750 \mathrm{~nm}$. Temperature differences between the average and any of the line pairs were less than $50-100 \mathrm{~K}$ and experimental uncertainties (95\% confidence) of the measurements were less than $50 \mathrm{~K}$.

Concentrations of major stable gas species $\left(\mathrm{N}_{2}, \mathrm{H}_{2} \mathrm{O}, \mathrm{H}_{2}, \mathrm{O}_{2}, \mathrm{CO}, \mathrm{CO}_{2}, \mathrm{CH}_{4}, \mathrm{C}_{2} \mathrm{H}_{2}, \mathrm{C}_{2} \mathrm{H}_{4}\right.$, $\mathrm{C}_{2} \mathrm{H}_{6}, \mathrm{C}_{3} \mathrm{H}_{6}, \mathrm{C}_{3} \mathrm{H}_{8}, \mathrm{C}_{6} \mathrm{H}_{6}$ and neon, the last being a tracer gas used to estimate effects of radial diffusion of lithium-containing species that were used to find $\mathrm{H}, \mathrm{OH}$ and $\mathrm{O}$ concentrations) were measured by sampling and gas chromatography. Experimental uncertainties (95\% confidence) of these measurements are estimated to be less than $10 \%$ for stable gas species having 
concentrations greater than $0.1 \%$, increasing to roughly $30 \%$ at the present limit of detection of stable gas species, brought to this level by repeated measurements to establish reliable calibrations and average concentration values for each species.

Soot primary particle diameters were measured using thermophoretic sampling and analysis by Transmission Electron Microscopy (TEM) and High Resolution Transmission Electron Microcopy (HRTEM). Thermophoretic soot sampling results are only reported here for the axes of the flames. Potential effects of contamination of these samples as the soot sampler traversed the flames when moving to-and-from the flame axes was established in two ways: (1) sampling in the region prior to the onset of soot formation along the axes of the flames (but where there was a well-developed annular soot-containing region near the edge of the region exhibiting yellow soot luminosity) properly indicated that no soot aggregates, that could have been deposited as the sampler passed through the annular soot-containing region, were present on the sampler for the sampling conditions used during the present study, and (2) the sampled soot exhibited only nearly constant primary soot particle diameters at each flame condition along the axis (e.g., the standard deviations of primary particle diameters were less than $10 \%$ ) rather than the widely-varying primary soot particle diameters that would be observed if off-axis soot particles were present in the sample. The experimental uncertainties (95\% confidence) of primary particle diameters at a point were estimated to be less than $10 \%$.

Streamwise gas velocities were measured using laser velocimetry. The experimental uncertainties ( $95 \%$ confidence) of these measurements were less than $5 \%$.

Measurements of $\mathrm{H}$ concentrations were carried out by deconvoluted absorption following the $\mathrm{Li} / \mathrm{LiOH}$ absorption technique of Neoh and coworkers. ${ }^{23-25}$ Correction for the radial diffusion of lithium-containing compounds was found from measurements of the concentrations trace levels of neon in the fuel stream, assuming that the diffusivities of the 
lithium-containing compounds and neon were similar. The $\mathrm{H}$ concentration measurements were calibrated using a premixed flame as discussed by $\mathrm{Xu}$ and Faeth,? similar to Neoh and coworkers. $^{23-25}$ Measurements using different seeding levels showed that effects of the lithium compounds used for the $\mathrm{H}$ concentration measurements were negligible, similar to past work. ${ }^{6.7}$ Experimental uncertainties (95\% confidence) of the $\mathrm{H}$ concentration measurements are estimated to be smaller than $30 \%$. Given measured concentrations of $\mathrm{H}, \mathrm{O}_{2}, \mathrm{H}_{2}$ and $\mathrm{H}_{2} \mathrm{O}$, values of $\mathrm{OH}$ and O concentrations were computed assuming partial equilibrium among these species following Neoh and coworkers, ${ }^{23-25}$ using the equilibrium constant data of Chase et al. ${ }^{44}$ This involved finding $\mathrm{OH}$ and $\mathrm{O}$ concentrations assuming partial equilibrium considering $\mathrm{H}, \mathrm{H}_{2} \mathrm{O}$ and $\mathrm{H}_{2}$ concentrations for fuel-rich conditions and $\mathrm{H}, \mathrm{H}_{2} \mathrm{O}$ and $\mathrm{O}_{2}$ concentrations for fuel-lean conditions. The experimental uncertainties of $\mathrm{OH}$ and $\mathrm{O}$ concentrations were comparable to those of $\mathrm{H}$ concentrations. The laminar premixed flame used to calibrate the $\mathrm{H}$ concentration measurements operated using the fuel port of the present burner, see $\mathrm{Xu}$ and Faeth ${ }^{6}$ for a summary of the properties of this flame.

\section{Test Conditions}

The present results involve measurements from nine test flames: three acetylenenitrogen-fueled flames drawn from the earlier work of Xu and Faeth, ${ }^{7}$ an ethylene-fueled flame, a propylene-nitrogen-fueled flame, a propane-fueled flame and three acetylene-benzene-nitrogenfueled flames, with the last six flames measured during the present investigation. The test conditions for all nine flames are summarized in Table 1. Nitrogen dilution of the fuel stream was found to be a convenient way to reduce soot concentrations in the flames, because rates of soot formation tend to be roughly proportional to the concentration of fuel at the burner exit, with little other effect on flame properties; therefore, it was used for the acetylene-, propyleneand acetylene-benzene-fueled flames in order to keep maximum soot volume fractions smaller than 2 ppm so that measurement problems due to large soot concentrations could be avoided. 
Luminous flame lengths were $80-103 \mathrm{~mm}$ whereas stoichiometric flame lengths (the vertical heights where the local fuel-equivalence ratios at the axis were unity) were $74-130 \mathrm{~mm}$. The stoichiometric flame temperatures in Table 1 were found from adiabatic combustion calculations using the algorithm of $\mathrm{McBride}$ et $a{ }^{45}$ Finally, acetone contamination of acetylene pointed out by Hamins et al. ${ }^{46}$ and Colket et al..$^{7,48}$ are not thought to be a problem for present measurements, based on evaluation of this effect by Xu and Faeth ${ }^{7}$ using Flames 1-3 summarized in Table 1.

\section{Results and Discussion}

\section{Soot Structure}

Soot particles observed during the present investigation were similar to those seen during earlier studies of soot processes in laminar premixed and diffusion flames, see Refs. 1-8 and references cited therein. Typical TEM (top with a length scale of $100 \mathrm{~nm}$ ) and HRTEM (bottom, with a length scale of $20 \mathrm{~nm}$ ) photographs of soot particles along the axis of the ethylene/air flame (Flame 4) are illustrated in Fig. 1. Images of soot particles for the other flames studied were qualitatively the same. Images of soot particles are provided for conditions near the onset of soot formation where primary soot particle diameters reach a maximum (left photographs), near the end of soot formation where soot concentrations reach a maximum (center photographs) and near stoichiometric conditions where soot oxidation is roughly $90 \%$ complete (on a mass basis) for this flame (right photographs). The TEM images indicate that soot particles consist of roughly spherical primary soot particles with the mean number of primary soot particles per aggregate progressively increasing with increasing elapsed time (or streamwise distance) in the flame. A non-intuitive feature of the results illustrated in Fig. 1 is that after an initial rapid increase of primary soot particle diameters, just after the onset of soot formation along the axis of the flames, mean primary soot particle diameters subsequently decrease with increasing distance from the burner exit in spite of effects of soot surface growth throughout the remainder of the soot formation region. This behavior has been observed for all the laminar jet diffusion 
flames studied in this laboratory, ${ }^{1-3,7}$ and will be discussed more fully when flame structure is discussed.

The HRTEM images in Fig. 1 also are similar to soot aggregates observed during past studies of soot formation in flames, see Lahay and Prado, ${ }^{49}$ Garo et al., ${ }^{50}$ Hess and Herd, ${ }^{51}$ Ishiguro et al. ${ }^{52}$ and references cited therein for other examples. In general, the primary soot particles near the maximum primary soot particle size position (left HRTEM photograph) and the maximum soot concentration position (center HRTEM photograph) exhibit an outer shell having a sheet-like structure parallel to the surface of the primary soot particle, and an inner core that appears to result from coalescence of several smaller primary soot particles near the soot nucleation condition. The irregular structure of the inner core is more evident after the shell-like surface layer has been largely oxidized away (right HRTEM photograph). Other evidence of the different character of the center and surface layers of primary soot particles is provided by the different densities and oxidation properties of the centers of primary soot particles compared to their near-surface conditions, see Neoh et al..$^{25}$

\section{Flame Structure}

Measurements of gas (soot) temperatures, streamwise gas velocities, soot volume fractions, primary soot particle diameters, concentrations of major gas species and concentrations of radical species $(\mathrm{H}, \mathrm{OH}$ and $\mathrm{O})$ are plotted as a function of height above the burner exit for an acetylene-nitrogen/air flame (Flame 2), the ethylene/air flame (Flame 4) and an acetylene-benzene-nitrogen/air flame (Flame 9) in Figs. 2-4. Note that the structure of the acetylene-nitrogen/air flame (Flame 2) illustrated in Fig. 2 is typical of the other acetylenenitrogen/air flames (Flames 1 and 3), that the structure of the ethylene/air flame (Flame 4) illustrated in Fig. 3 is typical of the propylene-nitrogen/air and propane/air flames (Flames 5 and 6), and that the structure of the acetylene-benzene-nitrogen/air flame (Flame 9) illustrated in Fig. 
4 is typical of the other acetylene-benzene-nitrogen/air flames (Flames 7 and 8). Elapsed times in the flames, found by integrating the streamwise velocity measurements along the axes of the flames, are indicated at the top of plots. These elapsed times are relative to the first streamwise measuring station where detectable soot volume fractions were observed $(z=10 \mathrm{~mm})$. The stoichiometric $(\phi=1)$, or flame sheet condition, is marked for the ethylene/air flame (Flame 4) illustrated in Fig. 3 (at $z=82 \mathrm{~mm}$ ), however, the flame sheet lies beyond the region illustrated for the acetylene-nitrogen/air flame (Flame 2) illustrated in Fig. 2 (at $z=106 \mathrm{~mm}$ ) and for the acetylene-benzene-nitrogen/air flame (Flame 9) illustrated in Fig. 4 (at $z=110 \mathrm{~mm}$ ). Thus, all properties shown for the acetylene-nitrogen/air and acetylene-benzene-nitrogen/air flames are for fuel-rich conditions. The ends of the luminous flame regions in Figs. $2-4$ are at $z=80,100$ and 90 mm although soot concentrations near these boundaries were too small to be accurately measured and reported using the present laser extinction technique. Finally, it is convenient to divide the present flames into two regions separated by the location of the maximum soot concentration condition, as follows: the region upstream of this condition where soot formation dominates other soot reaction processes and soot concentrations increase with increasing distance from the burner exit, which will be called the soot formation region, and the region downstream of this condition where soot oxidation dominates other soot reaction processes and soot concentrations decrease with increasing distance from the burner exit, which will be called the soot oxidation region.

Gas (soot) temperatures in Figs. 2-4 reach a broad maximum in the soot formation region somewhat before the flame sheet is reached. The temperature range in the soot formation regions of the present flames is relatively narrow, roughly $1600-1850 \mathrm{~K}$. Kent and Wagner ${ }^{53,54}$ and Boedeker and Dobbs ${ }^{55.56}$ have pointed out that maximum temperatures in soot-containing diffusion flames are significantly reduced from adiabatic flame temperatures due to continuum radiation heat losses from soot. The present flames, as well as earlier diffusion flames studied in 
this laboratory, ${ }^{1-3.7}$ exhibit maximum temperatures smaller than adiabatic flame temperatures (see Table 1), for similar reasons.

Gas velocities in Figs. 2-4 increase with increasing distance from the burner exit due to effects of buoyancy, e.g., burner exit velocities are $0.003-0.03 \mathrm{~m} / \mathrm{s}$ whereas maximum measured velocities are in excess of $2 \mathrm{~m} / \mathrm{s}$. This causes corresponding distortion of the elapsed time scale at the top of the figures.

Primary soot particle diameters reach maximum values relatively early in the soot formation region in Figs. 2-4, as already noted in connection with Fig. 1. This behavior is caused by accelerating soot primary particle nucleation rates with increasing streamwise distance, which is caused by progressively increasing $\mathrm{H}$ concentrations with increasing streamwise distance as discussed by $\mathrm{Xu}$ and Faeth. ${ }^{?}$ This behavior causes the relatively few primary soot particles formed near soot inception conditions, that become large due to long periods of soot surface growth in a region where acetylene concentrations are large, to be superseded by the much larger number of primary soot particles formed later in the sootformation region, that are smaller due to shorter periods of soot surface growth in regions where growth rates are reduced due to smaller acetylene concentrations. This trend is aided by the fact that soot growth remains relatively rapid near soot inception conditions, as noted by Tesner, ${ }^{57,58}$ which allows the few primary particles present at this location to grow relatively large.

Significant levels of soot formation (evidenced by the appearance of finite levels of soot volume fractions), are generally associated with conditions where detectable levels of $\mathrm{H}$ were first observed, e.g., where $\mathrm{H}$ concentrations exceed 10 ppm in Figs. 2-4. For all the fuels, this condition also involved relatively large acetylene concentrations, e.g., values of $4-10 \%$ by volume for the conditions illustrated in Figs. 2-4. Soot formation again became small when maximum soot concentrations were reached, which occurred in the presence of relatively large 
concentrations of $\mathrm{H}(100-200 \mathrm{ppm})$ where acetylene concentrations became smaller than roughly $1 \%$ by volume. An interesting feature of the maximum soot concentration condition where soot formation becomes small when benzene is a portion of the fuel, e.g., in Fig. 4, is that this event is definitely correlated with conditions where acetylene becomes small whereas the concentrations of benzene remain relatively constant in this region (see the region near the maximum soot concentration conditions in Fig. 4).

The concentrations of major stable gas species in Figs. 2-4 are similar to observations in other laminar diffusion flames that have been studied, for example, see Sunderland and coworkers. ${ }^{\mathrm{i}-3}$ When acetylene is the fuel, e.g., in Fig. 2 , its concentration progressively decreases with increasing distance from the burner exit. For fuels other than acetylene, e.g., Figs. 3 and 4, however, the original fuel generally'disappears-relatively soon within the soot formation region to yield hydrogen and hydrocarbon species that are relatively robust in high-temperature flame environments, particularly relatively stable acetylene. Acetylene is especially important as a fuel decomposition product because it is thought to be the major building block of both PAH, that leads to soot nucleation, as well as soot surface growth. ${ }^{12,17-20}$ Benzene as a fuel is an apparent exception to this behavior, see Fig. 4, but even benzene largely disappears near the burner exit, leaving a relatively small but nearly constant benzene concentration in the soot-containing region with benzene only finally disappearing near the flame sheet. In fact, concentration distributions of acetylene within flames fueled with hydrocarbons other than acetylene are qualitatively similar to concentration distributions of acetylene within flames fueled with acetylene. The final combustion products, $\mathrm{CO}_{2}$ and $\mathrm{H}_{2} \mathrm{O}$, increase with increasing streamwise distance throughout the soot formation region, reaching broad maxima near the flame sheet $(\phi=1)$. Intermediate combustion products associated with water-gas equilibrium, $\mathrm{CO}$ and $\mathrm{H}_{2}$, are present in relatively large concentrations throughout the soot formation region, reaching broad maxima somewhat 
upstream of the flame sheet. Finally, nitrogen concentrations remain relatively uniform for the flame regions illustrated in Figs. 2-4.

Concentrations of $\mathrm{O}_{2}$ either progressively increase with increasing distance from the burner exit (Figs. 2 and 3) or progressively increase as the flame sheet is approached after reaching a broad minimum near the burner exit (Fig. 4). The former behavior follows because $\mathrm{O}_{2}$ concentrations at the flame sheet are relatively large. The latter behavior is probably caused by some leakage of coflowing $\mathrm{O}_{2}$ into the fuel-rich region of the flames through the gap between the burner exit and the point where the flames are attached, similar to behavior observed by Mitchell et al. ${ }^{31}$ for a methane/air laminar coflowing jet diffusion flame. Thus, $\mathrm{O}_{2}$ is invariably present at concentrations on the order of $0.1 \%$ (by volume) throughout most of the soot formation region of the present flames. In addition, concentrations of fuel-like species, particularly $\mathrm{H}_{2}$ and $\mathrm{CO}$, penetrate well into the fuel-lean region. Thus, the present flames generally do not satisfy approximations made during simplified classical analysis of laminar diffusion flames in that there is considerable overlap of fuel- and oxidant-like species in the region of the flame sheet.

Concentrations of $\mathrm{OH}$ and $\mathrm{O}$ increase monotonically as the flame sheet is approached, whereas concentrations of $\mathrm{H}$ reach a broad maximum within the soot formation region before decreasing somewhat as the flame sheet is approached. Similar to recent numerical predictions of the structure of soot-containing laminar coflowing jet diffusion flames at atmospheric pressure involving methane/air and ethylene/air as reactants due to McEnally et al..$^{40}$ and Smooke et al., near-equilibrium radical concentrations (based on present measurements of stable species concentrations and temperatures and the thermochemical data of Chase et al. ${ }^{44}$ ) were observed near the onset of soot formation but $\mathrm{OH}$ concentrations eventually reach values 10-20 times larger than equilibrium concentrations near the flame sheet. In addition, concentrations of $\mathrm{H}$ exhibit superequilibrium properties at fuel-rich conditions similar to the superequilibrium 
properties of $\mathrm{OH}$. Concentrations of $\mathrm{O}$, however, become 100-1000 times larger than equilibrium concentrations as the flame sheet is approached; nevertheless, concentrations of $O$ generally are 100-1000 times smaller than $\mathrm{H}$ and $\mathrm{OH}$ concentrations throughout most of the soot formation region. Finally, species that past measurements in diffusion flames have shown to be responsible for soot surface growth $\left(\mathrm{C}_{2} \mathrm{H}_{2}\right.$ and $\left.\mathrm{H}\right),{ }^{7}$ and for soot surface oxidation $\left(\mathrm{O}_{2}\right.$ and $\left.\mathrm{OH}\right){ }^{8}$ are seen to all be present within the soot formation region; therefore, soot surface growth and oxidation proceed at the same time in the soot formation regions of the present diffusion flames. Notably, this behavior is also typical of past observations of soot surface growth in diffusion flames in this laboratory. ${ }^{1-3.7}$

\section{Soot Surface Growth Rates}

Past and present measurements were used to find soot surface growth rates for laminar premixed and diffusion flames. Major assumptions were identical to earlier work, ${ }^{1 \cdot 7}$ as follows: soot mass production is dominated by soot surface growth rather than primary soot particle nucleation, effects of diffusion (Brownian motion) and thermophoresis on soot motion are small so that soot particles convect along the axes of the flames at the local gas velocity, the density of soot is constant (taken to be $1850 \mathrm{~kg} / \mathrm{m}^{3}$ from Ref. 1), and the surface area available for soot growth is equivalent to constant diameter spherical primary soot particles that meet at a point. The justification of these assumptions and the detailed methods of finding soot surface growth rates from the present measurements are described in Refs. 1 and 7 and will not be repeated here. The experimental uncertainties (95\% confidence) of soot surface growth rates are estimated to be less than $30 \%$.

In order to interpret the present soot surface growth rates, gross soot surface growth rates were corrected for effects of soot surface oxidation because soot surface growth and oxidation proceed at the same time as just noted. A recent study of soot surface oxidation in laminar jet 
diffusion flames burning in coflowing air at atmospheric pressure, ${ }^{8}$ which included all the flames considered during the present investigation, indicated that soot surface oxidation in these flames proceeded via the $\mathrm{OH}$ soot surface oxidation mechanism of Neoh and coworkers, ${ }^{23,24}$ with nearly the same collision efficiency, after allowing for the relatively small contribution of direct soot oxidation based on the $\mathrm{O}_{2}$ soot surface oxidation mechanism of Nagle and StricklandConstable. ${ }^{21}$ For example, the $\mathrm{OH}$ collision efficiency of Neoh and coworkers, ${ }^{23,24}$ is 0.13 with an uncertainty ( $95 \%$ confidence) of \pm 0.03 based on measurements within premixed flames, whereas the $\mathrm{OH}$ collision efficiency of $\mathrm{Xu}$ et al. ${ }^{8}$ is 0.14 and with an uncertainty $(95 \%$ confidence) of \pm 0.04 based on measurements within diffusion flames. Thus, all the measurements of soot surface growth considered in the following, including earlier measurements in laminar premixed ${ }^{4,5}$ and diffusion flames, ${ }^{7}$ were corrected for effects of soot surface oxidation using the $\mathrm{OH}$ and $\mathrm{O}_{2}$ approach based on the measurements of Xu et al. ${ }^{8}$ It was found that effects of soot surface oxidation estimated in this way generally were small, except when soot surface growth rates became small toward the end of the soot formation region. In order to be conservative about potential effects of soot surface oxidation, however, determinations of soot surface growth rates corrected for effects of soot surface oxidation were limited to conditions where estimated soot surface oxidation rates never exceeded half the gross soot surface growth rates, similar to past work, e.g., Refs. 1-5 and 7.

In order to baseline the present estimates of soot surface growth rates with earlier studies of soot surface growth rates in laminar premixed and diffusion flames, ${ }^{1-5.7}$ soot surface growth rates were also corrected for effects of soot surface oxidation using the same method as these earlier studies. During these earlier studies, rates of soot surface oxidation were estimated using approximate earlier methods based on the assumption that soot oxidation occurred by reaction with stable oxygen-containing species because concentrations of radical species were unknown. The simplified soot oxidation mechanism used for these estimates was as follows: ${ }^{1-5,7}$ soot 
surface oxidation by $\mathrm{O}$ and $\mathrm{OH}$ was ignored; soot surface oxidation by $\mathrm{O}_{2}$ was based on the results of Nagle and Strickland-Constable; ${ }^{21}$ and soot surface oxidation by $\mathrm{H}_{2} \mathrm{O}$ and $\mathrm{CO}_{2}$ was estimated following Libby and Blake ${ }^{59,60}$ and Johnstone et al., ${ }^{61}$ which gave results similar to Bradley et al. ${ }^{62}$ Similar to the present approach considering soot surface oxidation by $\mathrm{OH}$ and $\mathrm{O}_{2}$, these estimates of net soot surface growth rates were limited to conditions where estimated soot surface oxidation rates never exceeded half the gross soot surface growth rates, which also was similar to past work in this laboratory. ${ }^{1-5,7}$ As a result of this conservative approach, soot surface growth rates corrected for soot oxidation were found using the present $\mathrm{O}_{2}$ and $\mathrm{OH}$ approach were essentially the same as those found using the earlier $\mathrm{O}_{2}, \mathrm{H}_{2} \mathrm{O}$ and $\mathrm{CO}_{2}$ approach.

Soot surface growth rates were interpreted using the HACA mechanisms of Colket and Hall $^{17}$ and Frenklach and coworkers ${ }^{18-20}$ in order to maintain consistency with past evaluations of these mechanisms based on measurements of soot surface growth rates in premixed ethylene/air and methane/oxygen flames, ${ }^{4,5}$ and in acetylene-nitrogen/air diffusion flames. ${ }^{7}$ In all cases, net soot surface growth rates corrected for soot surface oxidation were expressed, as follows:

$$
w_{g}=\alpha_{i} R_{i}
$$

where $\mathrm{i}=\mathrm{CH}$ or $\mathrm{FW}$ denotes reaction parameters for the HACA soot surface growth rate mechanisms of Colket and Hall ${ }^{17}$ and Frenklach and coworkers ${ }^{18-20}$ that were found from the measurements. The details of these mechanisms, the formulas for the $\mathrm{R}_{\mathrm{i}}$ and the reaction rate parameters used when computing values of the $\mathrm{R}_{\mathrm{j}}$, can be found in $\mathrm{Xu}$ et al. ${ }^{4}$ The parameters, $\alpha_{\mathrm{i}}$, are empirical steric factors on the order of unity, with $\alpha_{\mathrm{CH}}$ specified to be a constant ${ }^{17}$ and $\alpha_{\mathrm{Fw}}$ specified to be a function of temperature. ${ }^{18-20}$

As a first approximation for all the premixed and diffusion flames considered during this study, the $\mathrm{R}_{\mathrm{i}}$ are proportional to the product $[\mathrm{H}]\left[\mathrm{C}_{2} \mathrm{H}_{2}\right]$. Thus, values of $\mathrm{w}_{\mathrm{g}} /\left[\mathrm{C}_{2} \mathrm{H}_{2}\right]$ measured for 
the premixed ethylene/air flames by Xu et al., ${ }^{4}$ the premixed methane/oxygen flames by Xu et al., ${ }^{5}$ the acetylene-nitrogen/air diffusion flames by Xu and Faeth, ${ }^{7}$ and the present diffusion flames (after correcting all measurements for soot surface oxidation using the $\mathrm{OH}$ and $\mathrm{O}_{2}$ approach based on the measurements of Xu et al. ${ }^{8}$ ), are plotted as a function of $[\mathrm{H}]$ in Fig. 5, in order to provide a direct test of the main features of the HACA soot surface growth mechanism without the intrusion of uncertainties due to the numerous empirical parameters in the original detailed mechanisms. The results for premixed and diffusion flames in the figure are distinguished by denoting them by open and closed symbols, respectively. An empirical correlation of the measurements is also illustrated on the figure, obtained as an average for all the flames. There is a tendency for $\mathrm{w}_{\mathrm{g}} /\left[\mathrm{C}_{2} \mathrm{H}_{2}\right]$ to be slightly larger for diffusion flames than for premixed flames, at a given value of $[\mathrm{H}]$, when plotted in this manner. This is largely due to the approximation of the entire HACA mechanisms by the leading-term product, $\left[\mathrm{C}_{2} \mathrm{H}_{2}\right][\mathrm{H}]$, because differences between overall environments of the soot formation regions of premixed and diffusion flames affect the higher-order reaction terms of the HACA mechanisms (e.g., the nearequilibrium and superequilibrium radical concentrations of premixed and diffusion flames, respectively). It will be seen subsequently that no distinction between premixed and diffusion flames is observed when the full HACA mechanisms are considered. Nevertheless, the correlation of the results according to the crude $\left[\mathrm{C}_{2} \mathrm{H}_{2}\right][\mathrm{H}]$ approximation of the more complete HACA mechanisms is surprisingly good and soot surface growth rate properties in premixed and diffusion flames are reasonably consistent with each other in spite of the fundamental differences between the soot formation environments that can be seen by comparing the measured structures of the premixed flames, ${ }^{46}$ with those of the diffusion flames seen in Ref. 7 and Figs. 2-4. Finally, the strong effect of $[\mathrm{H}]$ on $\mathrm{w}_{\mathrm{g}}$, evident from the results illustrated in Fig. 5, combined with the near-equilibrium and strongly super-equilibrium behavior of $\mathrm{H}$ concentrations in premixed and diffusion flames, respectively, are responsible for the rather poor correlations, and enhanced apparent soot surface growth rates of diffusion flames compared to premixed flames, 
when attempts are made to correlate soot surface growth rates in terms of acetylene concentrations and temperatures, alone, see Sunderland et al. ${ }^{1}$

A more direct evaluation of the HACA mechanisms of soot surface growth rates is obtained by plotting $\mathrm{w}_{\mathrm{g}}$ directly as a function of $\mathrm{R}_{\mathrm{CH}}$ for the Colket and Hall ${ }^{17}$ mechanism and as a function of $\alpha_{\mathrm{FW}} \mathrm{R}_{\mathrm{FW}}$ (after correlating $\alpha_{\mathrm{FW}}$ as a function of temperature) for the mechanism of Frenklach and coworkers ${ }^{18-20}$. Results of this type for the Colket and Hall ${ }^{17}$ mechanism are illustrated in Fig. 6. In this figure, available measurements for both premixed and diffusion flames (after correcting all measurements for soot surface oxidation using the $\mathrm{OH}$ and $\mathrm{O}_{2}$ approach based on the measurements of $\mathrm{Xu}$ et $\mathrm{al}^{8}{ }^{8}$ ) are illustrated, along with the best-fit correlation for all the flames. The corresponding steric factor and its experimental uncertainties ( $95 \%$ confidence) is 1.0 with an uncertainty of \pm 0.2 . First of all, it is encouraging that the steric factor is on order of magnitude unity, as expected. ${ }^{17}$ Next, it is evident that use of the Colket and Hall ${ }^{17}$ meehanism -improves the correlation-of soot surface growth rates in Fig. 6, compared to the approximate correlation based on only the leading terms of the HACA mechanism illustrated in Fig. 5. In addition, the correlation of the soot surface growth rate results for premixed and diffusion flames using the Colket and Hall ${ }^{17}$ mechanism is essentially the same, i.e., there is no statistical significance for the differences between the steric factors found for the data from the premixed and diffusion flames. Finally, considering results for the diffusion flames alone, there clearly is no difference between estimates of $\mathrm{w}_{\mathrm{g}}$ based on the HACA mechanism of Colket and Hall $^{17}$ as the hydrocarbon fuel type is varied among the alkyne, alkene, alkane and aromatic fuels considered during the present investigation, i.e., there is no statistical significance to the differences between the values of the steric factors found for the various hydrocarbon fuels in diffusion flames that were considered during the present and past studies illustrated in Fig. 6 .

The correlation of $\alpha_{\mathrm{FW}}$ for soot surface growth for the complete data base of laminar premixed and diffusion flames (corrected for soot surface oxidation similar to the results 
illustrated in Figs. 5 and 6) was essentially the same as the results presented in the diffusion flame study of Xu and Faeth, ${ }^{7}$ which considered all the premixed flames but was limited to the acetylene/air diffusion flames; a complete plot of these results can be found in El-Leathy. ${ }^{9}$ The correlation of all the soot surface growth rate data considered here, assuming that $\alpha_{\mathrm{Fw}}(\mathrm{T})$ could be represented by an Arhennius function similar to Ref. 7, yielded:

$$
\alpha_{\mathrm{FW}}(\mathrm{T})=0.0017 \exp (12100 / \mathrm{T})
$$

with $\mathrm{T}(\mathrm{K})$. The subsequent plot of $\mathrm{w}_{\mathrm{g}}$ as a function of $\alpha_{\mathrm{FW}} R_{\mathrm{FW}}$ was qualitatively similar to the plot illustrated in Xu and Faeth. ${ }^{7}$ These results indicated that correlations of measurements in laminar premixed and diffusion flames were essentially the same, that effects of fuel type for laminar premixed and diffusion flames were small, that values of $\alpha_{\mathrm{FW}}$ were on the order of unity as expected, and that the negative activation energy implied by the argument of the exponential factor of Eq. (2) corresponds to behavior anticipated by Frenklach and coworkers ${ }^{18-20}$ for their soot surface growth mechanism.

Similar to earlier findings for soot surface growth rates, ${ }^{4,5,7}$ the HACA soot surface growth rate mechanisms of Colket and Hall ${ }^{17}$ and Frenklach and coworkers ${ }^{18-20}$ continue to be encouraging and they may eventually provide the basis for reliable methods to estimate soot surface growth rates in flame environments fueled with hydrocarbons. Uncertainties remain, however, about effects of pressure, about effects of temperature outside the limited range considered here, and about effects of PAH as fuels, on soot surface growth rates in premixed and diffusion flames.

\section{Conclusions}

Flame structure and soot surface growth rates were studied for coflowing laminar jet diffusion flames. Test conditions involved acetylene-, ethylene-, propylene-, propane-, and 
benzene-fueled diffusion flames burning in coflowing dry air at atmospheric pressure with the reactants at normal temperature and pressure as summarized in Table 1 (after supplementing present measurements with those of $\mathrm{Xu}$ and Faeth ${ }^{7}$ for acetylene-fueled diffusion flames). Information about soot surface growth rates in these diffusion flames was also supplemented by earlier measurements in laminar premixed ethylene/air and methane/oxygen flames due to Xu et al. ${ }^{4,5}$ that were also observed at atmospheric pressure with the reactants at normal temperature. The major conclusions of the study are as follows:

1. In all flames that have been considered thus far (except naturally for acetylene-fueled flames), the original fuel largely decomposes relatively early in the soot formation process, yielding species that generally are associated with soot surface growth and oxidation, e.g., $\mathrm{C}_{2} \mathrm{H}_{2}, \mathrm{H}$ and $\mathrm{OH}$, among others. The yields of these species are affected by the flame type (premixed or diffusion flame), the fuel and oxidizing species and the flame operating conditions, however, subsequent reaction of these_materials_during_processes_of soot surface growth is largely dependent on local flame conditions and is not materially affected by the fuel or oxidant type or whether these processes are occurring in premixed or diffusion flame environments.

2. Soot surface growth rates in laminar premixed and diffusion flames, for various fuel and oxidant types, agree within experimental uncertainties at comparable local conditions and could be correlated reasonably well using the HACA soot surface growth mechanisms of Colket and $\mathrm{Hall}^{17}$ and Frenklach and coworkers ${ }^{18-20}$ with the steric factors of both these mechanisms having values on the order of unity, as anticipated.

3. Measurements in all the diffusion flames indicate that $\mathrm{H}, \mathrm{OH}$ and $\mathrm{O}$ approach equilibrium near the start of the soot formation region but generally exhibit superequilibrium concentrations throughout the soot-containing region (with $\mathrm{H}$ and $\mathrm{OH}$ reaching superequilibrium ratios of 10-20 
and $O$ reaching superequilibrium ratios of $100-1000$, although actual concentrations of $O$ generally are much smaller than the concentrations of $\mathrm{H}$ and $\mathrm{OH}$ ).

4. Measurements in the diffusion flames showed that significant degrees of soot formation begins near the jet exit once $\mathrm{H}$ first appears in a prevailing condition where acetylene concentrations are relatively large and that soot formation ends near the flame sheet where acetylene disappears in a prevailing condition where $\mathrm{H}$ concentrations are relatively large. This behavior is consistent with soot surface growth being dominated by the HACA mechanisms as noted in connection with Conclusion No. 2. Finally, benzene was only observed for the benzenefueled flames where benzene concentrations were both constant and relatively small and (less than $1 \%$ by volume) throughout the soot-containing region and were not particularly correlated with either the onset or the end of soot formation.

5. The present investigation exploited recent measurements of soot surface oxidation rates in laminar diffusion flames (including all the flames considered here) due to Xu et al. ${ }^{8}$ in order to correct gross measurements of soot surface growth rates for simultaneous effects of soot surface oxidation. This involved estimating soot surface oxidation rates by $\mathrm{O}_{2}$ based on the results of Nagle and Strickland-Constable ${ }^{21}$ and by $\mathrm{OH}$ as proposed by Neoh and coworkers ${ }^{23-25}$ but using nearly the same $\mathrm{OH}$ collision efficiency of Xu et al. ${ }^{8}$ Corrected soot surface growth rates were only considered, however, in cases where estimated soot surface oxidation rates were less than half the gross soot surface growth rates for all flame conditions considered here, which is the same approach used during earlier studies where other mechanisms of soot surface oxidation were considered..$^{4,5,7}$ Due to this relatively conservative approach for correcting soot surface growth rates for effects of soot surface oxidation, however, present estimates of net soot surface growth rates were essentially unchanged from earlier results where soot surface oxidation was estimated using an approximate method based on the concentrations of stable species $\left(\mathrm{O}_{2}, \mathrm{H}_{2} \mathrm{O}\right.$ 
and $\mathrm{CO}_{2}$ ) because radical concentrations needed for the $\mathrm{OH} / \mathrm{O}_{2}$ soot surface oxidation mechanism were not known, e.g., Refs. 4, 5 and 7.

It should be recalled that measurements used for soot surface growth rate results reported here, e.g., Refs. 4, 5 and 7 and the present investigation, are limited to hydrocarbon-fueled flames at atmospheric pressure with the reactants initially at normal temperature. These conditions yielded ranges of properties for conditions where the soot surface growth rates were measured as follows: $\mathrm{H}$ atom concentrations of $3 \times 10^{-8}-2 \times 10^{-6} \mathrm{kgmol} / \mathrm{m}^{3} ; \mathrm{C}_{2} \mathrm{H}_{2}$ concentrations of $6 \times 10^{-6}-2 \times 10^{-3} \mathrm{kgmol} / \mathrm{m}^{3}$; temperatures of $1600-1850 \mathrm{~K}$; and original fuels involving alkynes, alkenes, alkanes and aromatics $\left(\mathrm{C}_{2} \mathrm{H}_{2}, \mathrm{C}_{2} \mathrm{H}_{4}, \mathrm{C}_{3} \mathrm{H}_{6}, \mathrm{C}_{3} \mathrm{H}_{8}\right.$, and $\left.\mathrm{C}_{6} \mathrm{H}_{6}\right)$; use of present correlations of soot surface growth rates for other flame conditions should be approached with caution.

\section{Acknowledgments}

-This research was supported-by NASA Grants NAG3-1245, 1878 and 2048 under the technical management of D.L. Urban and Z.-G. Yuan of the NASA Glenn Research Center.

\section{References}

${ }^{1}$ Sunderland, P.B., Köylü, Ü.Ö., and Faeth, G.M., "Soot Formation in Weakly Buoyant Acetylene-Fueled Laminar Jet Diffusion Flames Buming in Air," Combustion and Flame, Vol. 100, Nos. 1/2, 1995, pp. 310-322.

${ }^{2}$ Sunderland, P.B., and Faeth, G.M., "Soot Formation in Hydrocarbon/Air Laminar Jet Diffusion Flames," Combustion and Flame, Vol. 105, Nos. 1/2, 1996, pp. 132-146.

${ }^{3}$ Lin, K.-C., Sunderland, P.B., and Faeth, G.M., "Soot Nucleation and Growth in Acetylene/Air Laminar Coflowing Jet Diffusion Flames," Combustion and Flame, Vol. 104, No. 3, 1996, pp. 369-375.

${ }^{4}$ Xu, F., Sunderland, P.B., and Faeth, G.M., "Soot Formation in Laminar Premixed Ethylene/Air Flames at Atmospheric Pressure," Combustion and Flame, Vol. 108, 1997, pp. 471-493. 
${ }^{5} \mathrm{Xu}$, F., Lin, K.-C., and Faeth, G.M., "Soot Formation in Laminar Premixed Methane/Oxygen Flames at Atmospheric Pressure," Combustion and Flame, Vol. 115, Nos. 1/2, 1998, pp. $195-$ 209.

${ }^{6} \mathrm{Xu}, \mathrm{F}$., and Faeth, G.M., "Structure of the Soot Growth Region of Laminar Premixed Methane/Oxygen Flames," Combustion and Flame, Vol. 121, No. 4, 2000, pp. 640-650

${ }^{7} \mathrm{Xu}$, F., and Faeth, G.M., "Soot Formation in Laminar Acetylene/Air Diffusion Flames at Atmospheric Pressure," Combustion and Flame, Vol. 125, Nos. 1/2, 2001, pp. 804-819.

${ }^{8}$ Xu, F., El-Leathy, A.M., Kim, C.-H., and Faeth, G.M., "Soot Surface Oxidation in Laminar Hydrocarbon/Air Diffusion Flames at Atmospheric Pressure," Combustion and Flame, in press.

'Xu, F., "Soot Growth in Laminar Premixed Flames," Ph.D. Dissertation, Dept. Aerospace Engineering, The University of Michigan, 1999.

${ }^{10}$ El-Leathy, A.M., Effect of Hydrocarbon Fuel on Soot Surface Growth and Oxidation in Laminar Diffusion Flames, Ph.D. Dissertation, Mechanical Power Dept., Helwan University, Cairo, Egypt, 2002.

${ }^{11}$ Haynes, B. S., and Wagner, H. G., "Soot Formation," Progress in Energy and Combustion Science, Vol. 7, No. 4, 1981, pp. 229-273.

${ }^{12}$ Howard, J.B., "Carbon Addition and Oxidation Reactions in Heterogeneous Combustion and Soot Formation," Proceedings of the Combustion Institute, Vol. 23, 1990, pp. 1107-1127.

${ }^{13}$ Richter, H., and Howard, J.B.,"Formation of Polycyclic Aromatic Hydrocarbons and Their Growth to Soot - A Review of Chemical Reaction Pathways," Progress in Energy and Combustion Science, Vol. 26, Nos. 4-6, 2000, pp. 565-608.

${ }^{14}$ Kennedy, I.M., "Models of Soot Formation and Oxidation," Progress in Energy and Combustion Science, Vol. 23, No. 2, 1997, pp. 95-132.

${ }^{15}$ Harris, S.J., and Weiner, A.M., "Surface Growth of Soot Particles in Premixed Ethylene/Air Flames," Combustion Science and Technology, Vol. 31, 1983, Nos. 3 and 4, pp. 155-167.

${ }^{16}$ Ramer, E.R., Merklin, J.F., Sorensen, C.M., and Taylor, T.W. "Chemical and Optical Probing of Premixed Methane/Oxygen Flames," Combustion Science and Technology, Vol. 48, Nos. 5 and 6, 1986, pp. 241-255. 
${ }^{17}$ Colket, M.B., and Hall, R.J., "Successes and Uncertainties in Modelling Soot Formation in Laminar Premixed Flames," Soot Formation in Combustion (H. Bockhorn, ed.), Springer-Verlag, Berlin, 1994, pp. 442-470.

${ }^{18}$ Frenklach, M., and Wang, H., "Detailed Modeling of Soot Particle Nucleation and Growth," Proceedings of the Combustion Institute, Vol. 23, 1999, pp. 1559-1556.

${ }^{19}$ Frenklach, M., and Wang, H., "Detailed Modeling of Soot Particle Nucleation and Growth," Soot Formation in Combustion (H. Bockhorn, ed.), Springer-Verlag, Berlin, 1994, pp. 165-192.

${ }^{20}$ Kazakov, A.,Wang, H., and Frenklach, M., "Detailed Modeling of Soot Formation in Laminar Premixed Ethylene Flames at a Pressure of 10 Bar, Combustion and Flame, Vol. 110, Nos. 1/2, 1995, pp. 111-120.

${ }^{21}$ Nagle, J., and Strickland-Constable, R.F., "Oxidation of Carbon Between 1000-2000 ${ }^{\circ} \mathrm{C}$," Proceedings of Fifth Carbon Conference, Vol. 1, 1962, pp. 154-164.

${ }^{22}$ Park, C., and Appleton, J.P., "Shock-Tube Measurements of Soot Oxidation Rates," Combustion and Flame,-Vol.-20;-No. 3, 1973, pp. 369-379.--

${ }^{23}$ Neoh, K.G., Howard, J.B., and Sarofim, A.F., "Soot Oxidation in Flames," Particulate Carbon (D.C. Siegla and B.W. Smith, ed.), Plenum Press, New York, 1980, pp. 261-277.

${ }^{24}$ Neoh, K.G., Soot Burnout in Flames, Ph.D. Dissertation, Massachusetts Institute of Technology, Cambridge, Massachusetts, 1980.

${ }^{25}$ Neoh, K.G., Howard, J.B., and Sarofim, A.F., "Effect of Oxidation on the Physical Structure of Soot," Proceedings of the Combustion Institute, Vol. 20, 1984, pp. 951-957.

${ }^{26}$ Garo, A., Lahaye, J., and Prado, G., "Mechanisms of Formation and Destruction of Soot Particles in a Laminar Methane-Air Diffusion Flame," Proceedings of the Combustion Institute, Vol. 21, 1986, pp. 1023-1031.

${ }^{27}$ Garo, A., Prado, G., and Lahaye, J., "Chemical Aspects of Soot Particles Oxidation in a Laminar Methane-Air Diffusion Flame," Combustion and Flame, Vol. 79, Nos. 3 and 4, 1990, pp. 226-233. 
${ }^{28}$ Hardiquert, M., Cessou, A., Stepowski, D., and Coppalle, A., "OH and Soot Concentration Measurements in a High-Temperature Láminar Diffusion Flame," Combustion and Flame, Vol. 111, No. 4, 1997, pp. 338-349.

${ }^{29}$ Balthasar, M., Heyl, A., Mauss, F., Schmitt, F., and Bockhorn, H., "Flamelet Modeling of Soot Formation in Laminar Ethylene/Air Diffusion Flames," Proceedings of the Combustion Institute, Vol. 26, 1996, pp. 2369-2377.

${ }^{30}$ Bai, K.W., Balthasar, M., Mauss, F., and Fuchs, L., "Detailed Soot Modeling in Turbulent Jet Diffusion Flames," Proceedings of the Combustion Institute, Vol. 27, 1998, pp. 1623-1630.

${ }^{31}$ Mitchell, R.E., Sarofim, A.F., and Clomberg, L.A., "Experimental and Numerical Investigation of Confined Laminar Diffusion Flames," Combustion and Flame, Vol. 37, No. 3, 1980, pp. 227244.

${ }^{32}$ Santoro, R.J., Semerjian, H.B., and Dobbins, R.A., "Soot Particle Measurements in Diffusion Flames," Combustion and Flame, Vol. 51, No. 2, 1983, pp. 203-218.

${ }^{33}$ Smyth, K.C., Miller, J.H., Dorfman, R.C., Mallard, W.G., and Santoro, R.J., "Soot Inception in a Methane/Air Diffusion Flame as Characterized by Detailed Species Profiles," Combustion and Flame, Vol. 62, No. 2, 1985, pp. 157-181.

${ }^{34}$ Santoro, R.J., Yeh, T.T., Horvath, J.J., and Semerjian, H.G., "The Transport and Growth of Soot Particles in Laminar Diffusion Flames," Combustion Science and Technology, Vol. 53, Nos. 2+3, 1987, pp. 89-115.

${ }^{35}$ Puri, R., Santoro, R.J., and Smyth, K.C., "The Oxidation of Soot and Carbon Monoxide in Hydrocarbon Diffusion Flames," Combustion and Flame, Vol. 97, No. 2, 1994, pp. 125-144.

${ }^{36}$ Puri, R., Santoro, R.J., and Smyth, K.C., "The Oxidation of Soot and Carbon Monoxide in Hydrocarbon Diffusion Flames," Combustion and Flame, Vol. 102, Nos. 1/2, 1995, pp. 226-228.

${ }^{37}$ Saito, K., Williams, F.A., and Gordon, A.S., "Structure of Laminar Coflow Methane-Air Diffusion Flames," Journal of Heat Transfer, Vol. 108, No. 3, 1986, pp. 640-648.

${ }^{38}$ McEnally, C.S., and Pfefferle, L.D., "Aromatic and Linear Hydrocarbon Concentration Measurements in a Non-Premixed Flame," Combustion Science and Technology, Vols. 115-117, Nos. 1-6, 1996, pp.183-209. 
${ }^{39}$ McEnally, C.S., and Pfefferle, L.D., "Flow Time Effects on Hydrocarbon Growth and Soot Formation in Coflowing Methane/Air Non-Premixed Flames," Proceedings of the Combustion Institute, Vol. 27, 1998, pp. 1539-1547.

${ }^{40}$ McEnally, C.S., Schaffer, A.M., Long, M.B., Pfefferle, L.D., Smooke, M.D., Colket, M.B., and Hall, R.J., "Computational and Experimental Study of Soot Formation in a Coflow Laminar Ethylene Diffusion Flame," Proceedings of the Combustion Institute, Vol. 27, 1998, pp. 14971505.

${ }^{41}$ Smooke, M.D., McEnally, C.S., Pfefferle, L.D., Hall, R.J., and Colket, M.B., "Computational and Experimental Study of Soot Formation on a Coflow, Laminar Diffusion Flame," Combustion and Flame, Vol. 117, Nos. 1/2, 1999, pp. 117-139.

${ }^{42}$ Dalzell, W.H., and Sarofim, A.F., "Optical Constants of Soot and Their Application to Heat Flux Calculations," Journal of Heat Transfer, Vol. 91, No. 1, 1969, pp. 100-104.

${ }^{43}$ Krishnan, S.S., Lin, K.-C., and Faeth, G.M., "Optical Properties in the Visible of Overfire Soot in Large Buoyant Turbulent Diffusion Flames," Journal of Heat Transfer, Vol. 122, No. 3, 2000, pp. 517-524.

${ }^{44}$ Chase, M.W., Jr., Davies, C.A., Downey, J.R., Jr., Frurip, D.J., McDonald, R.A., and Syverud, A.N., JANAF Thermochemical Tables, $3^{\text {rd }}$ ed., Journal of Physical Chemistry Reference Data, Vol. 14, Supplement No. 1, 1986, p. 1211.

${ }^{45}$ McBride, B.J., Reno, M.A., and Gordon, S., CET93 and CETPC: An Interim Updated Version of the NASA Lewis Computer Program for Calculating Complex Chemical Equilibrium with Applications, NASA Technical Memorandum 4557, Washington, D.C., 1994.

${ }^{46}$ Hamins, A., Gordon, A.S., Saito, K., and Seshadri, K., "Acetone Impurity in Acetylene from Tanks," Combustion Science and Technology, Vol. 45, Nos. 5+6, 1986, pp. 309-310.

${ }^{47}$ Colket, M.B, III, Seery, D.J., and Palmer, H.B., "The Pyrolysis of Acetylene Initiated by Acetone," Combustion and Flame, Vol. 75, Nos. 3 and 4, 1989, pp. 343-366.

${ }^{48}$ Colket, M.B, III, Seery, D.J., and Palmer, H.B., "On Impurity Effects in Acetylene Pyrolysis," Combustion and Flame, Vol. 84, Nos. 3 and 4, 1991, pp. 434-437. 
${ }^{49}$ Lahaye, J., and Prado, G., "Morphology and Internal Structure of Soot and Carbon Blacks," Particulate Carbon (D.C. Siegla and G.W. Smith. eds.), Plenum Press, New York, 1981, pp. 3355.

${ }^{50}$ Garo, A., Lahaye, J., and Prado, G., "Mechanisms of Formation and Destruction of Soot Particles in a Laminar Methane-Air Diffusion Flame," Proceedings of the Combustion Institute, Vol. 21, 1986, pp. 1023-1031.

${ }^{51}$ Hess, W.M., and Herd, C.R., "Microstructure, Morphology and General Physical Properties," Carbon Black (J.-B. Donoret, R.C. Bansal, and M.-J. Wang, eds.), Marcel Dekker, New York, 1993, pp. 89-173.

${ }^{52}$ Ishiguro, T., Takatori, Y., and Akihama, K., "Microstructure of Diesel Soot Particles Probed by Electron Microscopy: First Observations of Inner Core and Outer Shell," Combustion and Flame, Vol. 108, Nos. 1/2, 1997, pp. 231-234.

${ }^{53}$ Kent, J.H., -and Wagner, H.Gg., "Why do Diffusion Flames Emit Smoke?," Combustion Science and Technology, Vol. 41, No. 1, 1984, pp. 245-269.

${ }^{54}$ Kent, J. H., and-Wagner, H. Gg.; "Temperature and-Fuel Effects in Sooting Diffusion Flames," Proceedings of the Combustion Institute, Vol. 20, 1984, pp. 1007-1015.

${ }^{55}$ Boedecker, L.R., and Dobbs, G.M., "Soot Distribution and CARS Temperature Measurements in Axisymmetric Laminar Diffusion Flames with Several Fuels," Proceedings of the Combustion Institute, Vol. 21, 1986, pp. 1097-1105.

${ }^{56}$ Boedecker, L.R., and Dobbs, G.M., "CARS Temperature Measurements in Sooting Laminar
Diffusion Flames," Combustion Science and Technology, Vol. 46, Nos. 3-6, 1986, pp. 301-323.

${ }^{57}$ Tesner, P.A., "Formation of Dispersed Carbon by Thermal Decomposition of Hydrocarbons," Proceedings of the Combustion Institute, Vol. 7, 1958, p. 546-556.

${ }^{58}$ Tesner, P.A., "Dispersed Carbon Formation by Acetylene Self-Combustion," Proceedings of the Combustion Institute, Vol. 8, 1960, p. 627-633.

${ }^{59}$ Libby, P.A., and Blake, T.R., "Theoretical Study of Buming of Carbon Particles," Combustion and Flame, Vol. 36, No. 2, 1979, pp. 139-169. 
${ }^{60}$ Libby, P.A., and Blake, T.R., "Burning of Carbon Particles in the Presence of Water Vapor," Combustion and Flame, Vol. 41,No. 2, 1981, pp. 123-147.

${ }^{61}$ Johnstone, J.F., Chen, C.Y., and Scott, D.S., "Kinetics of the Steam-Carbon Reaction in Porous Graphite," Industrial Engineering Chemistry, Vol. 44, 1952, pp. 1564-1569.

${ }^{62}$ Bradley, D., Dixon-Lewis, G., El-Din Habik, S., and Mushi, E.M.J., "The Oxidation of Graphite Powder in Flame Reaction Zones," Proceedings of the Combustion Institute, Vol. 20, 1984, pp. 931-940. 
Table 1 Summary of test laminar jet diffusion flames ${ }^{\mathrm{a}}$

\begin{tabular}{|c|c|c|c|c|c|c|c|c|c|}
\hline Flame & 1 & 2 & 3 & 4 & 5 & 6 & 7 & 8 & 9 \\
\hline Fuel & $\mathrm{C}_{2} \mathrm{H}_{2}$ & $\mathrm{C}_{2} \mathrm{H}_{2}$ & $\mathrm{C}_{2} \mathrm{H}_{2}$ & $\mathrm{C}_{2} \mathrm{H}_{4}$ & $\mathrm{C}_{3} \mathrm{H}_{6}$ & $\mathrm{C}_{3} \mathrm{H}_{8}$ & $\mathrm{C}_{6} \mathrm{H}_{6}$ & $\mathrm{C}_{6} \mathrm{H}_{6}$ & $\mathrm{C}_{6} \mathrm{H}_{6}$ \\
\hline Fuel in fuel stream (\% by vol.) & 16.9 & 15.1 & 17.3 & 100.0 & $: 18.8$ & 100.0 & 0.6 & 1.3 & 2.2 \\
\hline $\mathrm{C}_{2} \mathrm{H}_{2}$ in fuel stream (\% by vol. $)^{b}$ & -- & $\cdots$ & $\cdots$ & $\vdots-\cdots$ & --- & --- & 14.0 & 10.2 & 5.5 \\
\hline $\mathrm{N}_{2}$ in fuel stream (\% by vol.) & 83.1 & 84.9 & 82.7 & '--- & 81.2 & -- & 85.4 & 88.5 & 92.3 \\
\hline Fuel stream flow $(\mathrm{cc} / \mathrm{s})^{\mathrm{c}}$ & 26.10 & 29.90 & 31.30 & 5.52 & 16.62 & 3.20 & 28.92 & 29.37 & 30.02 \\
\hline Dry air coflow (cc/s) $)^{\mathrm{c}}$ & 94.7 & 94.7 & 94.7 & 292.0 & 222.0 & 222.0 & 160.0 & 160.0 & 160.0 \\
\hline Luminous flame length (mm) & 82 & 80 & 103 & 100 & 100 & 100 & 90 & 90 & 90 \\
\hline Stoich. flame length (mm) & 100 & 106 & 116 & 81 & 74 & 79 & 95 & 130 & 110 \\
\hline Stoich. flame temperature $(\mathrm{K})^{\mathrm{d}}$ & 2380 & 2320 & 2390 & 2370 & 2150 & 2260 & 2140 & 2050 & 1900 \\
\hline
\end{tabular}

${ }^{\mathrm{a}}$ Laminar round coflowing jet diffusion flames with a $34.8 \mathrm{~mm}$ inside diameter fuel port and a $60 \mathrm{~mm}$ inside diameter concentric dry air port, both directed vertically upward. Ambient temperature and pressure of $294 \pm 2 \mathrm{~K}$ and $98 \pm 1 \mathrm{kPa}$. Gas purities (\% by vol.) as follows: $\mathrm{N}_{2}=99.9 \%, \mathrm{O}_{2}=99.6 \%, \mathrm{C}_{2} \mathrm{H}_{2}=99.6 \%, \mathrm{C}_{2} \mathrm{H}_{4}=99.5 \%, \mathrm{C}_{3} \mathrm{H}_{6}=99.5 \% ; \mathrm{C}_{3} \mathrm{H}_{8}=99.5 \%$; liquid $\mathrm{C}_{6} \mathrm{H}_{6}$ purity=99.0\%; dry air coflow consisted of $79 \% \mathrm{~N}_{2}$ and $21 \% \mathrm{O}_{2}$.

${ }^{b}$ Unless acetylene is the fuel in which case the concentration of acetylene in the fuel stream is indicated by the $\%$ by vol. fuel in the fuel stream.

${ }^{c}$ Volume flow rate based on standard conditions of $300 \mathrm{~K}$ and $101.3 \mathrm{kPa}$.

${ }^{\mathrm{d}}$ Adiabatic flame temperature for stoichiometric combustion of the fuel stream in dry air with the reactants at $300 \mathrm{~K}$ and combustion at $101.3 \mathrm{kPa}$. 


\section{List of Figures}

Fig. 1 TEM (top, with a length scale of $100 \mathrm{~nm}$ ) and HRTEM (bottom) with a length scale of $20 \mathrm{~nm}$ ) photographs of soot aggregates along the axis of the ethylene/air laminar jet diffusion flame at atmospheric pressure (Flame 4). Figure 1a is at the maximum primary particle diameter location $(\mathrm{z} \sim 35 \mathrm{~mm})$, Fig. $1 \mathrm{~b}$ is at the maximum soot volume fraction location $(z \sim 55 \mathrm{~mm})$, and Fig. $1 \mathrm{c}$ is at nearly at the end of the soot-containing region where soot oxidation is roughly $90 \%$ complete $(z \sim 80 \mathrm{~mm})$.

Fig. 2 Measured soot and flame properties of an acetylene-fueled laminar jet diffusion flame burning in coflowing air at atmospheric pressure (Flame 2, fuel stream of $15.1 \%, \mathrm{C}_{2} \mathrm{H}_{2}$ and $84.9 \% \mathrm{~N}_{2}$ by volume, from $\mathrm{Xu}$ and Faeth $^{7}$ ).

Fig. 3 Measured soot and flame properties of an ethylene-fueled laminar jet diffusion flame burning in coflowing air at atmospheric pressure (Flame 4, fuel stream of $100 \% \mathrm{C}_{2} \mathrm{H}_{4}$ by volume).

Fig. 4 Measured soot and flame properties of an acetylene-benzene-fueled laminar jet diffusion flame burning in coflowing air at atmospheric pressure (Flame 9, fuel stream of $2.2 \% \mathrm{C}_{6} \mathrm{H}_{6}, 5.5 \% \mathrm{C}_{2} \mathrm{H}_{2}$ and $92.3 \% \mathrm{~N}_{2}$ by volume).

Fig. 5 Soot surface growth rates (corrected for soot surface oxidation) as a function of acetylene and $\mathrm{H}$ concentrations for laminar flames at atmospheric pressure. Measurements of premixed ethylene/air flames from Xu et al., ${ }^{4}$ measurements of premixed methane/oxygen flames from $\mathrm{Xu}$ et al., ${ }^{5}$ measurements of acetylene/air diffusion flames from $\mathrm{Xu}$ and Faeth, ${ }^{7}$ and measurements of ethylene/air, propylene/air, propane/air, and acetylene-benzene/air diffusion flames from the present investigation.

Fig. 6 Soot surface growth rates (corrected for soot surface oxidation) in terms of the HACA mechanism of Colket and $\mathrm{Hall}^{17}$ for laminar flames at atmospheric pressure. Measurements of premixed ethylene/air flames from $\mathrm{Xu}$ et al., ${ }^{4}$ measurements of premixed methane/oxygen flames from $\mathrm{Xu}$ et al., ${ }^{5}$ measurements of acetylene/air diffusion flames from $\mathrm{Xu}$ and Faeth, ${ }^{7}$ and measurements of ethylene/air, propylene/air, propane/air, and acetylene-benzene/air diffusion flames from the present investigation. 

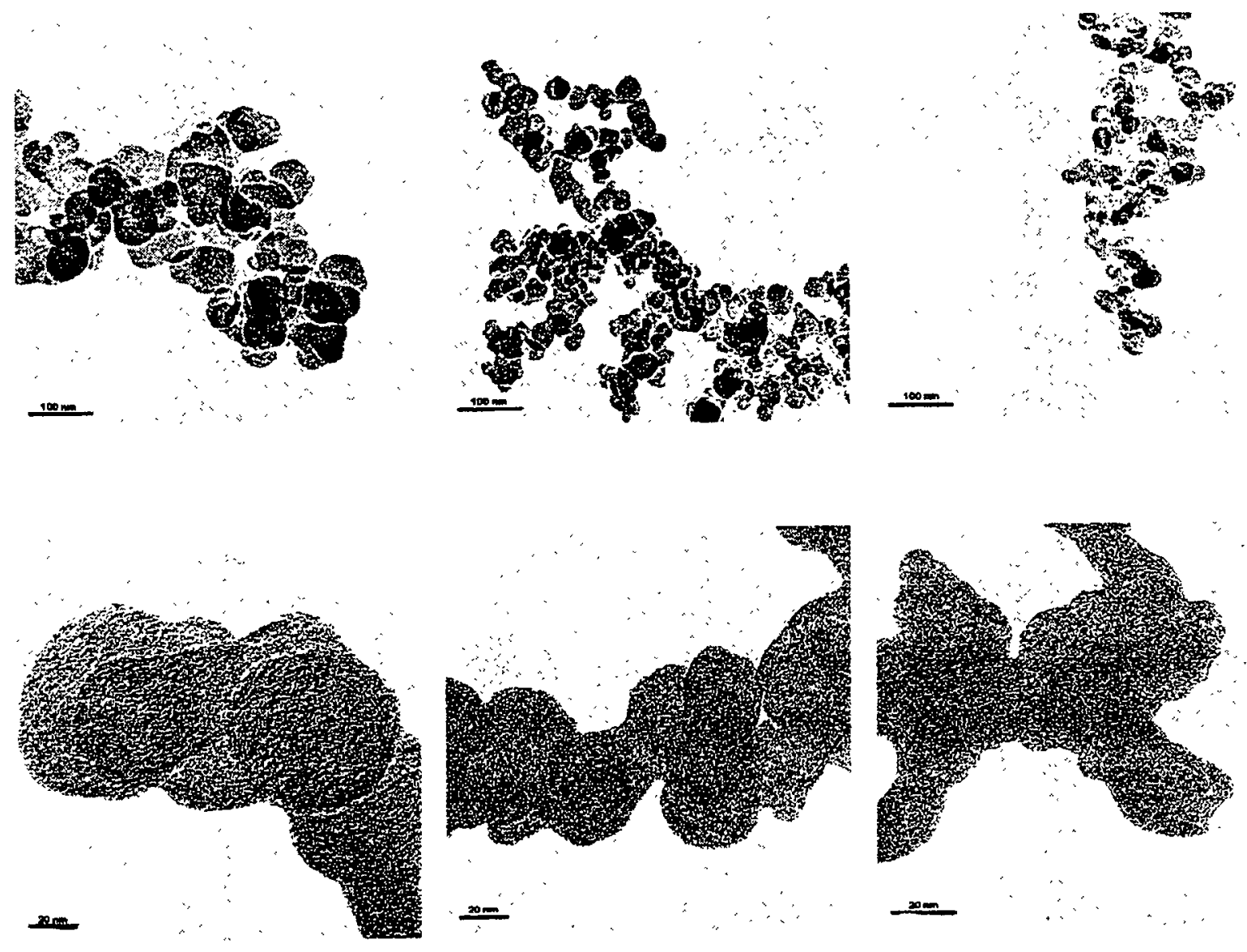

$$
\begin{aligned}
& 76:
\end{aligned}
$$

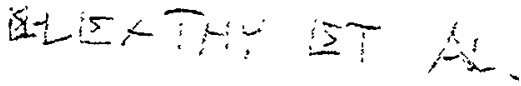




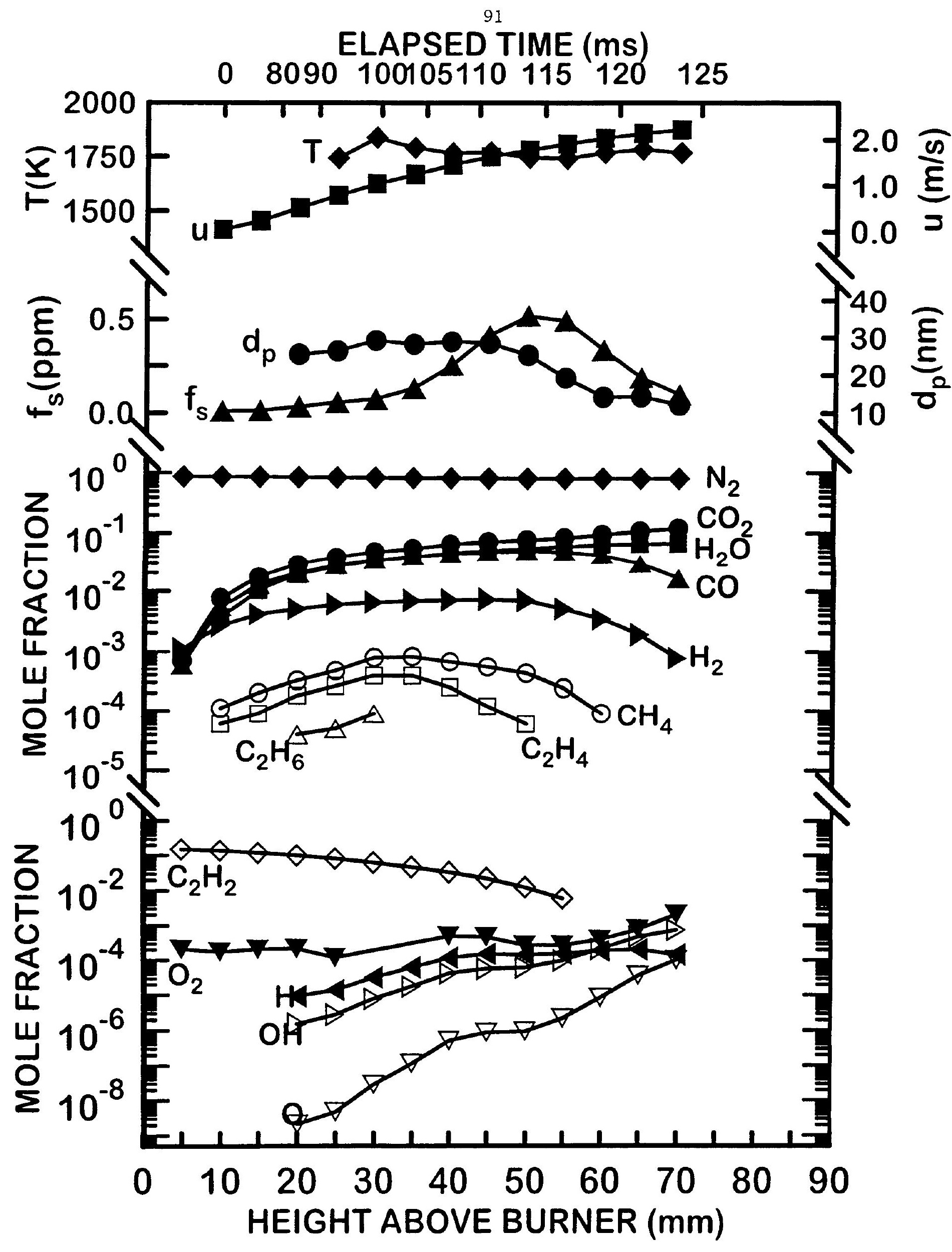


ELAPSED TIME (ms)

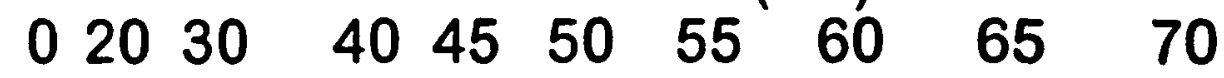

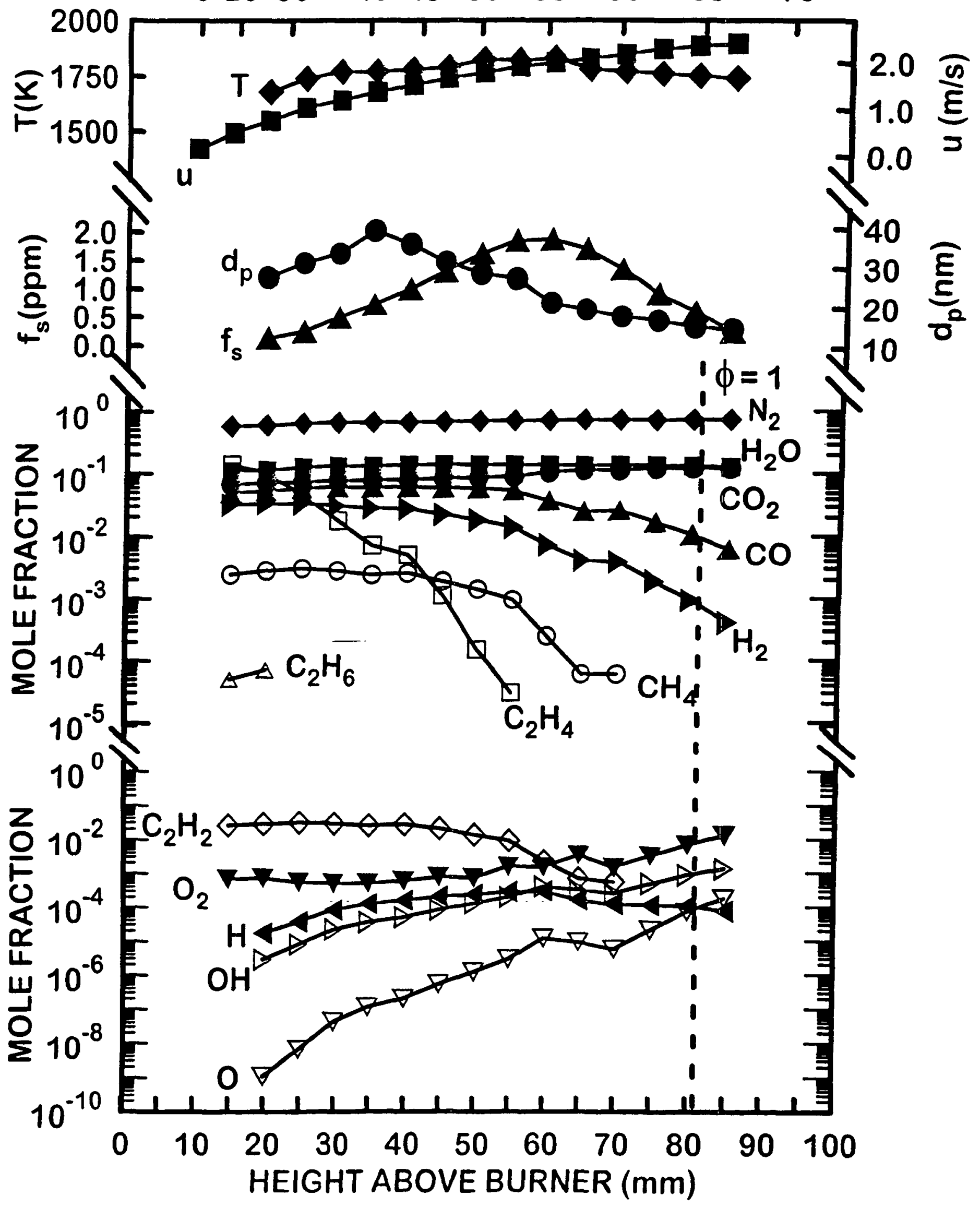




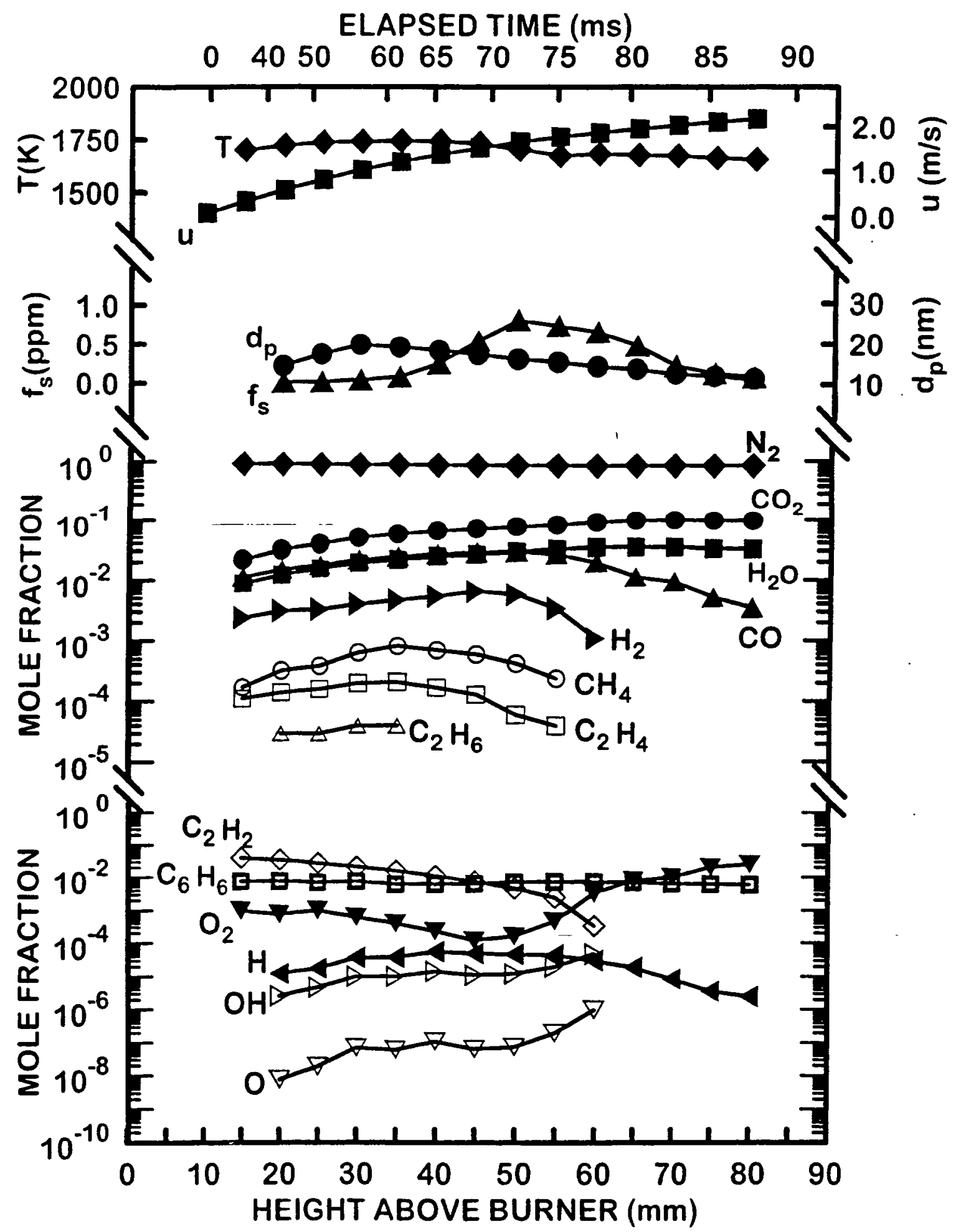

$B Z-\angle L D T N G G T A L, F=16,4$. 


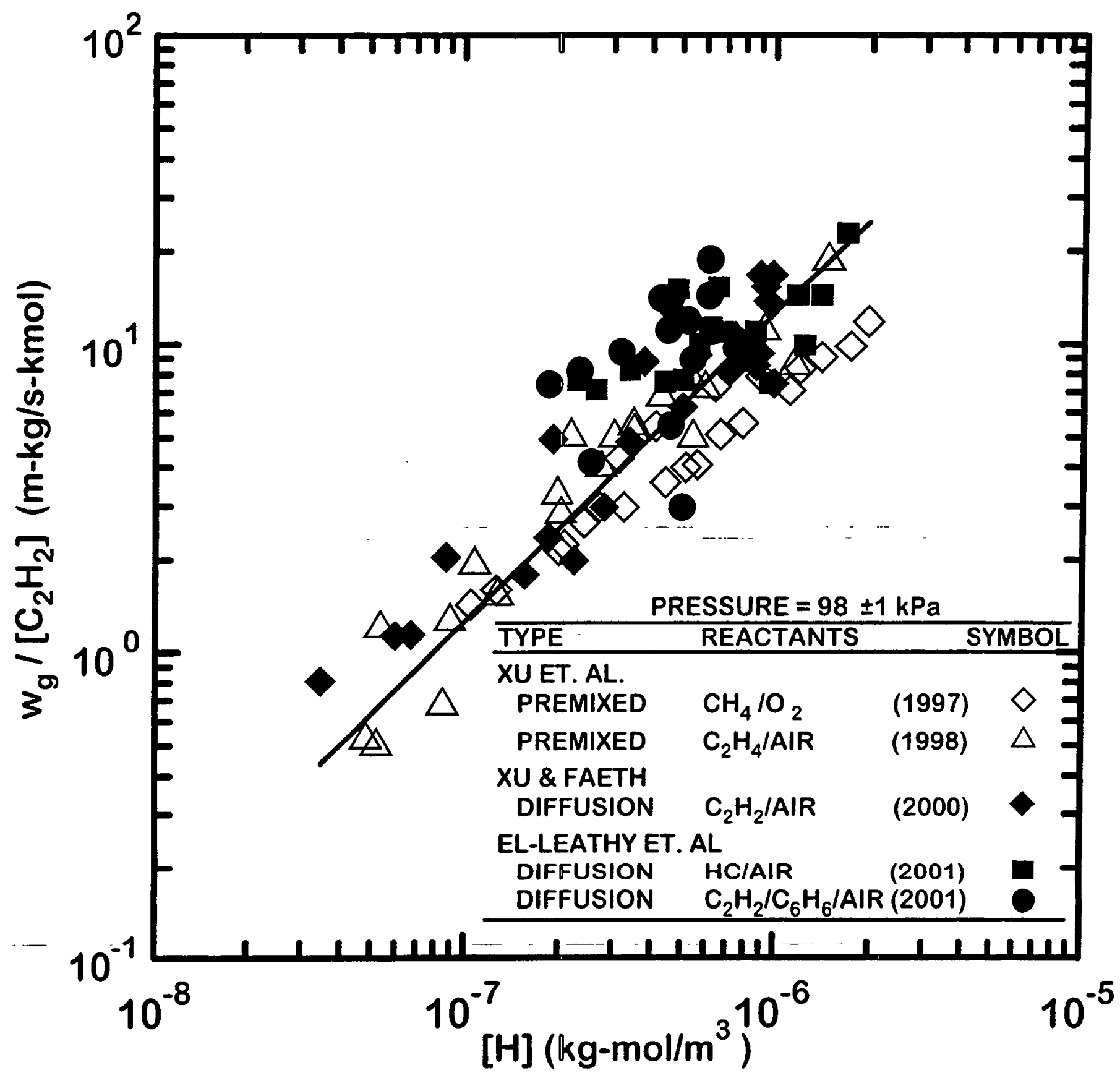




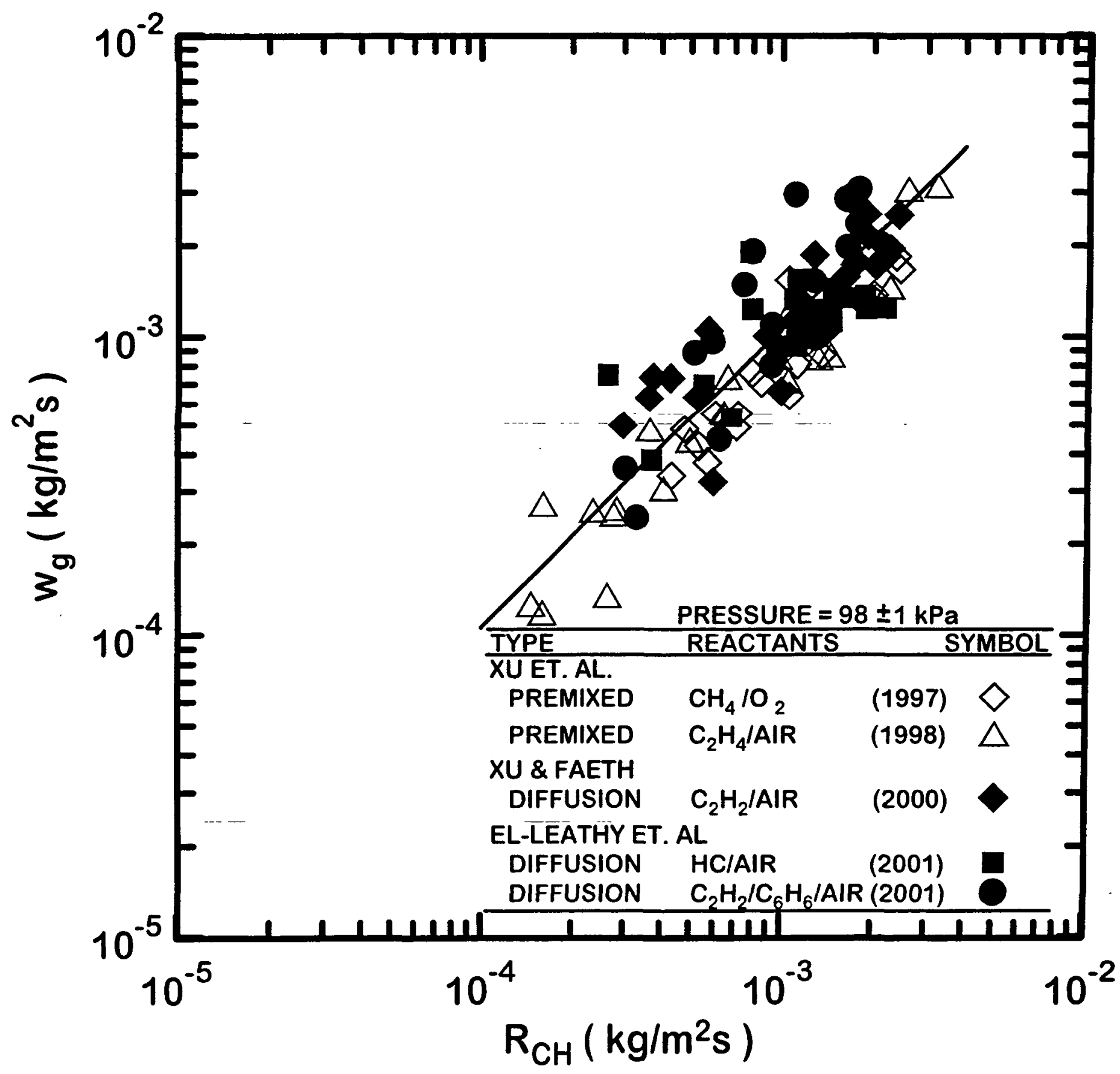

